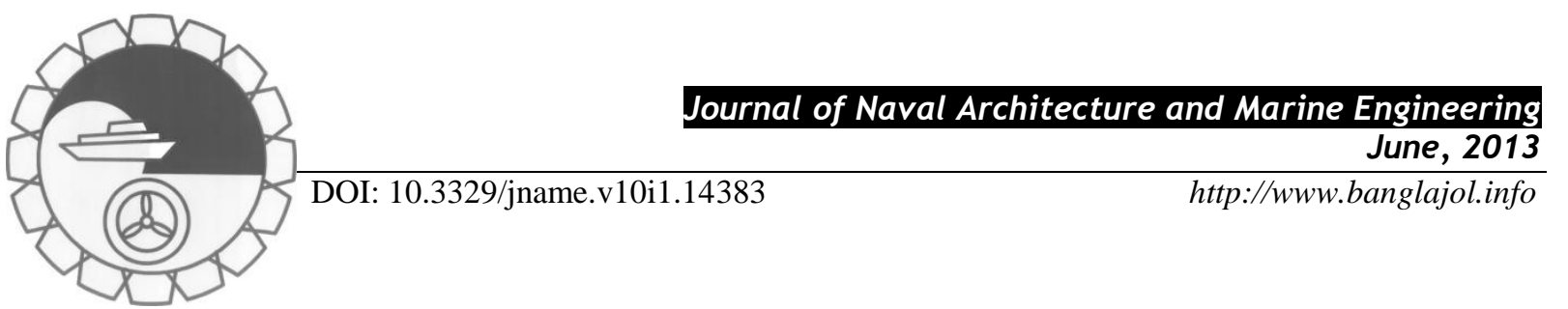

\title{
NUMERICAL SIMULATION OF 2D HYDRODYNAMIC IMPACT OF WEDGE AND SHIP SECTION AT VARIABLE VELOCITY
}

Md. Mashiur Rahaman ${ }^{1 *}$, Hiromichi Akimoto ${ }^{2}$ and Md. Ashim Ali ${ }^{1}$

${ }^{1}$ Department of Naval Architecture \& Marine Engineering, Bangladesh University of Engineering \& Technology, Dhaka1000, Bangladesh, E-mail: mashiurrahaman@name.buet.ac.bd

${ }^{2}$ Visiting Professor, Division of Ocean Systems Engineering (OSE), Korean Advanced Institute of Science \& Technology (KAIST), Daejeon 304-701, Republic of Korea

\begin{abstract}
:
A commercial CFD code Fluent $6.3^{\circledR}$ is used to simulate non-linear free surface flow and compute the impact load during variable velocity water entry of $2 D$ wedge and ship section. The code uses the finite volume method to solve the conservation of mass and momentum equations to obtain simulated flow field. The interface between water and air was modeled using volume of fluid (VOF) method. Wedge section with 30 degree dead-rise angle and a ship section are numerically simulated. Time history of impact force and pressures at distinct locations are predicted; and compared with existing experimental results and other numerical methods. Present numerical results show good agreement with experimental measurements.
\end{abstract}

Keywords: Numerical simulation, hydrodynamic impact, variable velocity.

\section{Introduction}

Slamming problems have increased attention recently by various research groups due to increase of cargo transport by sea, use of light and sophisticated materials for constructions of ships, ship speed for reduction of voyage time and the size of ship. The first comprehensive review on slamming has been reported by SNAME (1993). Faltinsen (2000) reported various slamming problems in ship and ocean structures with particular emphasis on hydro-elastic response. Faltinsen et al. (2004) presented the up-to-date reviews of the state-of-art research work as well as future challenges on the slamming problems in marine applications. Kapsenburg (2011) reviewed the published literature on ship slamming in waves in context of practical applicability of various theoretical methods proposed and different experiments carried out. The previous works carried out related to present research topic is mentioned in this section.

\subsection{Water entry of $2 D$ sections}

Slamming has challenged many researchers since von Karman's work. He idealized the impact as 2D wedge entry problem on calm water surface to estimate the water impact load on a seaplane during landing with small deadrise angle. Here, deadrise angle means the angle between the body surface and the impacting still water plane. Flat plate approximation is applied in von Karman's model without considering the water surface deformation and gravity effects. Wagner (1932) further developed von Karman's theory by taking into account of the local elevation of water. Wagner's models consider two fluid domains. Inner domain is for the jet flow at the intersection between body and free surface. The outer domain, the body boundary condition and the equipotential dynamic free surface condition were transformed into a horizontal line. The kinematic free surface condition was utilized to determine the intersection point between the free surface and the body in the outer domain. Better predictions of hydrodynamic loads and peak impact pressures can be obtained by Wagner's model for small deadrise angle. However, one cannot claim that Wagner's model gives better results than that of von Karman's because three-dimensional effects will reduce the loads and that after some time, for instance, gravity will affect the flow. Cointe and Armand (1987) demonstrated how this local solution can be matched with outer flow. The approach is further extended for studying the water impact of section with more general shape by Howison et al. (1991). A prominent advantage of numerical method is that there are no restrictions for the shape of geometry and entry speed. Also gravity can be included optionally. Therefore, numerical methods are extensively used by the researchers for solving the water entry problems of 2D sections with non-linear free surface conditions. In the early stage of numerical solution for water entry problems, boundary element method (BEM) based on potential flow was very popular and widely used. However, rapid advancement in computational resources and development of various robust and efficient solution algorithm, Reynolds averaged 
Navier-Stokes (RaNS) based solver is very popular now-a-days. By using potential-flow based method, progress has been made for solving water entry problems. However, there are difficulties for these methods to treat highly distorted or breaking free surfaces, especially the compressed air when the deadrise angle of wedge section is close to zero degree. These difficulties can be overcome by employing the computational fluid dynamics (CFD) methods based on solving Navier-Stokes equations. Moreover, application of CFD method for water entry problem is compared to numerical method based on potential flow theory.

\subsection{Bow flare slamming of ships}

Slamming on the flare region of bow part causes local and global structural damages. Usually, the shape of bow flare can be concave, V-shaped or wedge section. Therefore, studies of the water entry of a wedge section were also the cases motivated by problems of bow flare slamming. Arai and Matsunaga (1989) applied the method developed by Arai et al. (1987) to simulate water entry of a bow flare ship section into initially calm water with the consideration of gravity effect. It is found that for the case with large roll angle, high pressures appear over a large area of the bow flare when it impacts the water. Later, Arai et al. (1995) performed calculations for the water impact of different ship sections and found that the initial bottom slamming on a bow-flare section can generate separated water flow which will impact on the bow flare at a later stage and cause very high pressures on the bow. Tao and Incecik (1996) investigated the large-amplitude motions and bow flare slamming pressures in regular waves. For predicting ship motions in the time domain, non-linear restoring, damping and fluid momentum were considered. They used momentum slamming theory and Wagner theory to predict the bow flare slamming pressures. A satisfactory correlation between the results of predictions and model test measurements was obtained.

In rough seas, due to high-amplitude ship motions, bow of a ship's hull lifted totally out of water and then impacts the free surface. It is therefore necessary to study the water entry of ship like sections. However, many challenging physical and numerical problems are obviously easier to study properly by two-dimensional cases. Two-dimensional method also gives guidance on how to treat the three-dimensional flow properly during water entry. After the work of von Karman, many researches have been performed on water entry problems both analytically and numerically. But most of the numerical study is performed using boundary element method (BEM) based on potential theory and there is few works by using Reynolds averaged Navier-Stokes based computational fluid dynamics (CFD) method. During water entry, local pressure prediction on the sectional geometry is mostly effected by formation of jet due to free surface movement. This free surface movement which is because of viscosity can be modeled easily in RaNS based CFD method whereas viscous effects are neglected in potential flow based BEM. In present study, a commercial CFD code ANSYS FLUENT ${ }^{\circledR}$ is used to simulate the water entry of a 30 degree wedge and a bow-flare ship section with variable velocity. The aim of studying $2 \mathrm{D}$ sections in present research is to investigate the effects of velocity variation during water entry.

\section{Reference Experiment}

Present numerical model based on computational fluid dynamics (CFD) technique is validated with the drop tests carried out at MARINTEK by Zhao et al. (1996). This section describes a short detail of the drop test for better understanding of the readers. A free-falling rig was used for the tests. The rig consists of four different parts like
i. The vertical guide
ii. The trolley
iii. A rotatable horizontal beam and
iv. Test sections

The shape of the test sections are shown in Fig. 1. The total test sections are divided into three parts, one measuring section with a dummy section on each side. The measuring section is connected to the rig using two force transducers. The main data for the test set up for the sections are summarized in Table 1.

\section{Numerical Method}

\subsection{Governing equations and algorithms}

In ANSYS FLUENT ${ }^{\circledR}$, solution of the governing integral equations for conservation of mass and momentum is obtained by control-volume-based technique that consists of:

- Division of the domain into discrete control volumes using a pre-processor. 
- Integration of the governing equations on the individual control volumes to construct algebraic equations for the discrete dependent variables.

- Linearization of the discrete equations and solution for the linear equation system to yield updated values of the dependent variables.

(a)
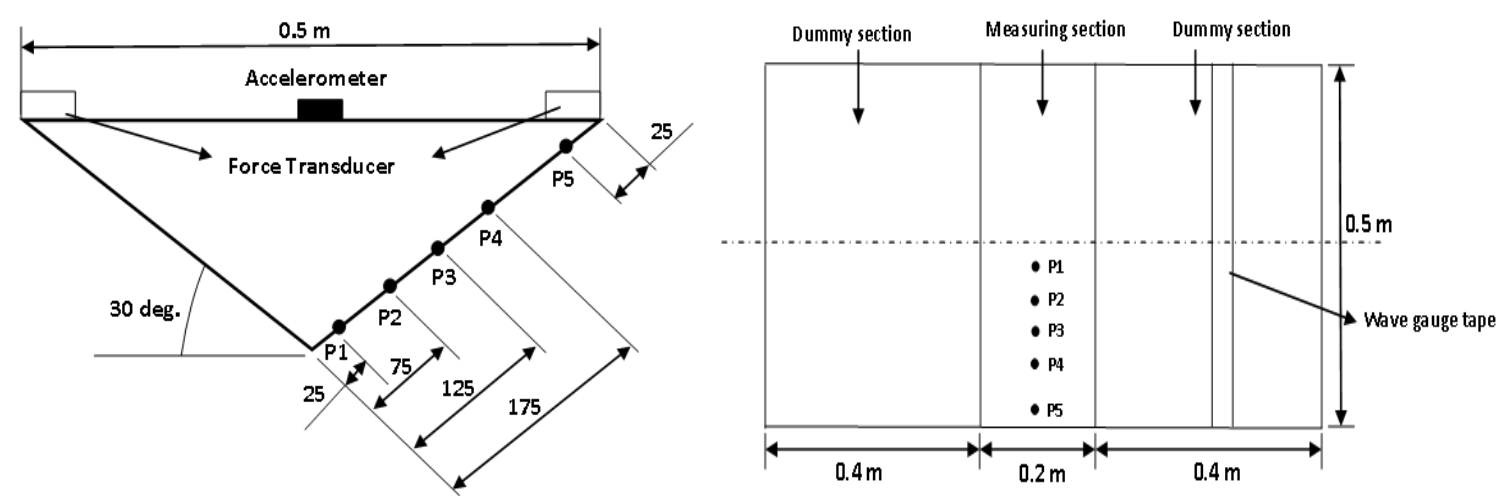

(b)
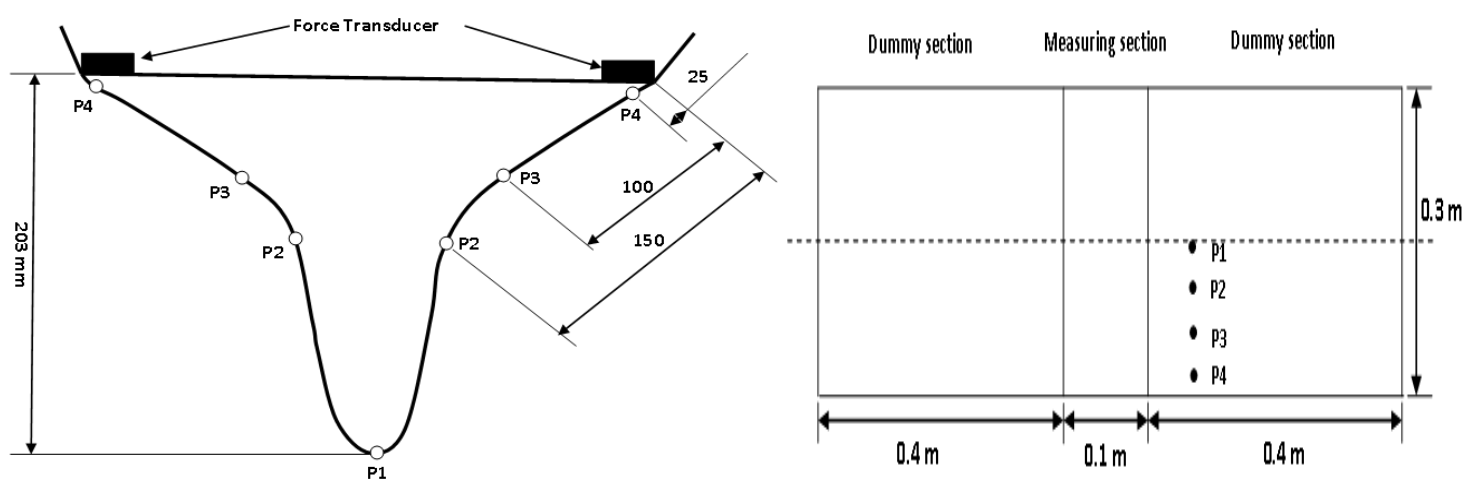

Fig. 1: Test section geometry and location of pressure gauge; a) wedge section, b) bow flare section, Zhao et al. (1996).

Table 1: Details of drop test sections Zhao et al. (1996).

\begin{tabular}{|l|r|r|}
\hline Particulars & Wedge (30deg.) & Bow flare \\
\hline Breadth & $0.50[\mathrm{~m}]$ & $0.32[\mathrm{~m}]$ \\
\hline Vertical distance from keel to knuckle & $0.29[\mathrm{~m}]$ & $0.203[\mathrm{~m}]$ \\
\hline Length of measuring section & $0.20[\mathrm{~m}]$ & $0.10[\mathrm{~m}]$ \\
\hline Length of each dummy section & $0.40[\mathrm{~m}]$ & $0.45[\mathrm{~m}]$ \\
\hline Total length & $1.00[\mathrm{~m}]$ & $1.00[\mathrm{~m}]$ \\
\hline Weight of drop rig (without ballast) & $141[\mathrm{~kg}]$ & $161[\mathrm{~kg}]$ \\
\hline Ballast weight & $100[\mathrm{~kg}]$ & $100[\mathrm{~kg}]$ \\
\hline Total weight of rig & $241[\mathrm{~kg}]$ & $261[\mathrm{~kg}]$ \\
\hline Weight of measuring section & $14.5[\mathrm{~kg}]$ & $6.9[\mathrm{~kg}]$ \\
\hline
\end{tabular}

The pressure-based segregated solution algorithm is employed to obtain a conversed numerical solution of the governing equations. Details of this solution algorithm can be found in FLUENT ${ }^{\circledR}$ user's guide. Quadratic 
upwind interpolation (QUICK) scheme is used for discretization in space. This scheme is of higher order accuracy, which is of great importance when the flow is at large angles to the grid. Viscous effects can be included but in present analyses, it is neglected because of its' small effects and as is the normal practice in water-entry problems. Therefore, for inviscid flow, the governing equations to be solved are the continuity equation and Euler's equation based on conservation of mass and momentum. The equations are solved sequentially using the semi-implicit method for pressure-linked equations (SIMPLE) algorithm. The Volume of fluid (VOF) method is used for modeling free surface. In VOF a variable is introduced for each fluid. This variable tells what fraction of that particular fluid is in the cell and the total of these variables for all fluids sums up to unity in every cell. The fluids share a single set of momentum equations and the volume fraction of each fluid is tracked throughout the domain. The fluid properties in a cell are dependent on the volume fractions of the fluid within it. The free surface occurs at cells that have volume fractions of one half for each of the two adjacent fluids. ANSYS FLUENT ${ }^{\circledR}$ provides different explicit and implicit discretization schemes for interpolation near the free surface. In present analysis time-dependent explicit geometric reconstruction interpolation scheme is used. This scheme represents the interface between fluids using a piecewise-linear approach and it is the most accurate in the current CFD solver. It assumes that the interface between two fluids has a linear slope within each cell, and uses this linear shape for calculation of the advection of fluid through the cell faces. The solution steps of this scheme are;

- $\quad$ Calculating the position of the linear interface relative to the center of each partially-filled cell, based on information about the volume fraction and its derivatives in the cell.

- Calculating the advecting amount of fluid through each face using the computed linear interface representation and information about the normal and tangential velocity distribution on the face.

- Calculating volume fraction in each cell using the balance of fluxes calculated using the previous step.

\subsection{Boundary conditions}

In the simulation domain, the body is held stationary and flow past it is achieved by having a velocity inlet at the bottom of the domain. At the top of the domain, there is a pressure boundary set at atmospheric pressure to allow outflow of excess air. The sectional geometry is defined as wall boundary condition with slip and the far end of the domain is defined as wall boundary conditions with free slip. Geometrical symmetry about the centerline has allowed the flow to be simulated in half of the domain.

\subsection{Fluid properties}

The water is treated as incompressible. The default values of fluid properties at room temperature for fresh water and air are used with density of $998.2 \mathrm{~kg} / \mathrm{m}^{3}$ for water and $1.293 \mathrm{~kg} / \mathrm{m}^{3}$ for air.

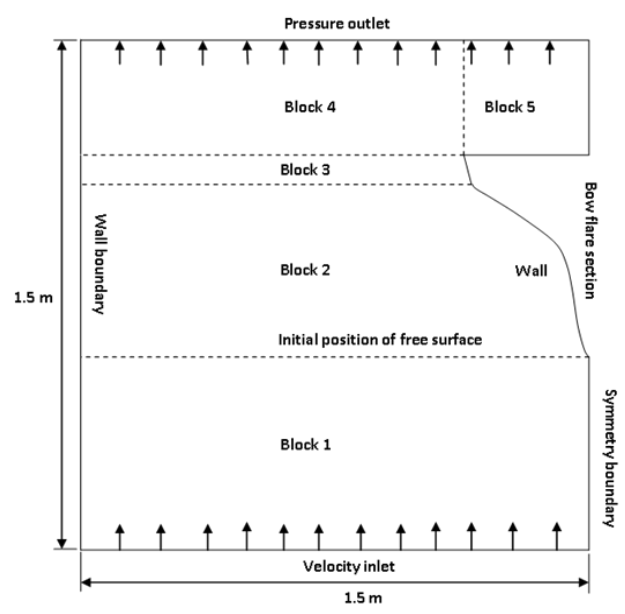

Fig. 2: Computational domain for 2D numerical simulation of water entry.

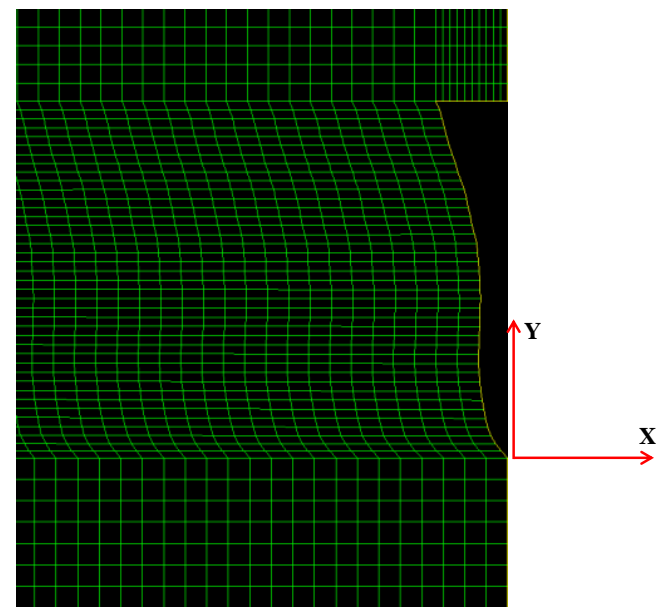

Fig. 3: Close-up view of grid distributions along the ship section for $2 \mathrm{D}$ simulations. 


\subsection{Computational domain and grid}

The size of computational domain shown in Fig. 2 is $1.5 \mathrm{~m}$ wide by $1.5 \mathrm{~m}$ high and it is divided into 5 (five) blocks. The grid is generated using body-fitted co-ordinates. Multi-block structured grid is used to avoid high skewness of the mesh in curved section. The nodal distribution from which the grid is generated is defined along each of the edges of these blocks. Initial position of free surface is defined by the horizontal line coinciding with the apex for the wedge section and the bottom for ship section. Minimum grid spacing is kept along the body section to capture the movement of free surface. Fig. 3 shows the close-up view of grid distributions along the ship section

A suitable grid density is found by repeating simulations with increasing density until a grid density independent solution is achieved. The grid size for wedge and bow flare section is shown in Table 2. Grid independent solution of the time history of impact force for a ship section is illustrated in Fig. 4.

Table 2: Particulars of grid

\begin{tabular}{|l|c|c|}
\hline Block & $\begin{array}{l}\text { Wedge } \\
\text { section }\end{array}$ & $\begin{array}{c}\text { Bow flare } \\
\text { section }\end{array}$ \\
\hline Block 1 & $120 \times 60$ & $120 \times 60$ \\
\hline Block 2 & $120 \times 40$ & $120 \times 50$ \\
\hline Block 3 & $120 \times 10$ & $120 \times 10$ \\
\hline Block 4 & $120 \times 30$ & $120 \times 30$ \\
\hline Block 5 & $10 \times 40$ & $10 \times 40$ \\
\hline Total & $\mathbf{1 7 , 2 0 0}$ & $\mathbf{1 8 , 4 0 0}$ \\
\hline
\end{tabular}

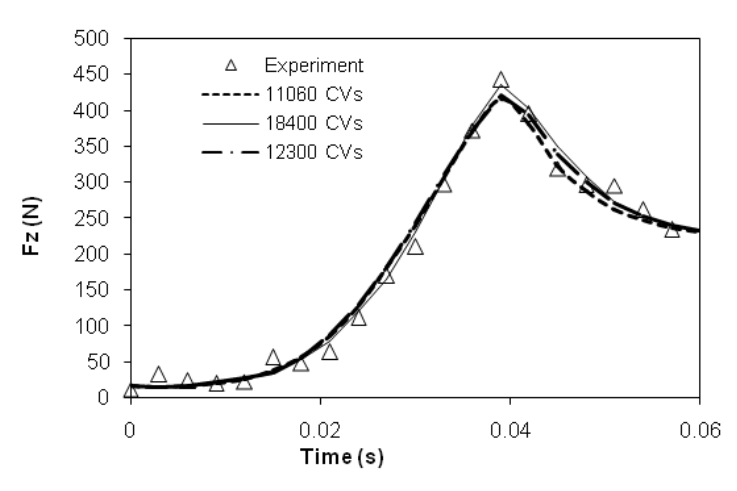

Fig. 4: Time history of impact force for a ship section showing the effects of grid density

\subsection{Solver}

Based on the minimum grid spacing, it is found that for stable solution, the Courant number needed to be less than 0.15 . During the solution, the level to which the sum of normalized residuals must drop before going on to the next time step is set to $1.0 \mathrm{e}^{-03}$. The minimum time step size for wedge and bow flare section is $2.5 \mathrm{e}-05$.

\subsection{Incorporation of deceleration effects}

A variation in drop velocity of the geometrical section over impact period is defined as deceleration effects. With experimental data, Zhao et al. (1996) shows that the impact velocities do not remain constant during the whole impact period. It varies depending upon the geometrical shape and the mass of the section itself. The experimental drop velocities for wedge section and bow flare section are shown in Fig. 5 and 6 respectively. Initial impact velocities for the wedge and bow flare sections are 6.15 and 2.416 meter/sec. Observations of the experimental data reveals that the total impact periods for the wedge section and bow flare section are around 0.025 and 0.08 seconds respectively.

Implementation of the velocity variations during the numerical solution is relatively straight forward if the impact velocity profile is known priori. In the present numerical method deceleration effect is implemented by fitting a forth order polynomial over the experimental velocity profile as a function of impact time. The fitted polynomial functions are;

For wedge sections,

$$
V(t)=6.15+22.82 t-78021 t^{2}+21276 t^{3}-65456 t^{4}, 0.0 \leq t \leq 0.025 \mathrm{sec}
$$

For bow flare sections,

$$
V(t)=2.416+3.82 t+326.31 t^{2}-7255.5 t^{3}+39381 t^{4}, 0.0 \leq t \leq 0.08 \mathrm{sec}
$$




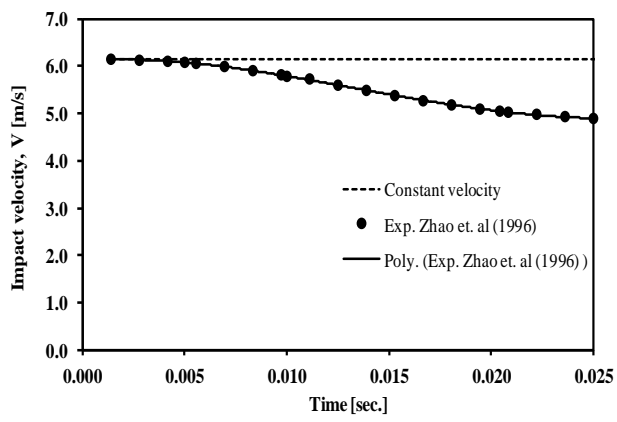

Fig. 5: Experimental drop velocity of wedge section (Zhao et al., 1996)

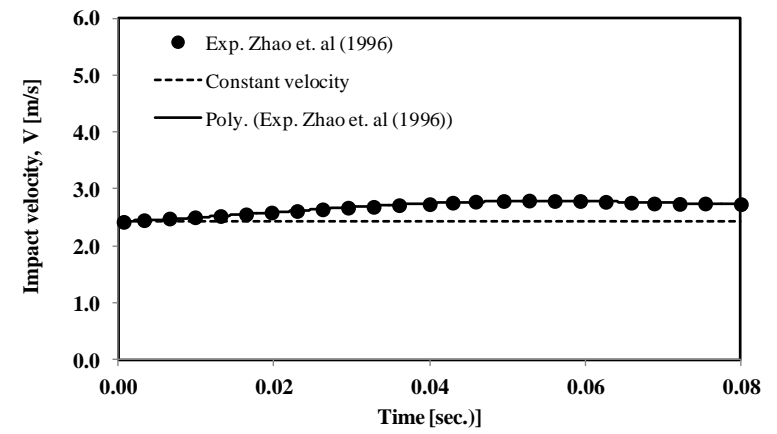

Fig. 6: Experimental drop velocity of bow flare section (Zhao et al., 1996)

\section{Numerical Results}

Results evaluated during the present study are time history of local pressure and it's distributions along the boundary of the impacting body, and vertical force on the sections. All computed results are compared with experimental results of Zhao et al. (1996) and numerical results of Muzaferija et al. (2000) and Reddy et al. (2002). Muzaferija et al. (2000) and Reddy et al. (2002) used Reynolds averaged Navier-Stokes based computational fluid dynamics (CFD) method with constant entry velocity. In the reference experiment, pressure and its' time history are measured at five points for wedge section and at four points for ship section.

Pressure is non-dimensionalized based on density of water and entry velocity whereas depth is nondimensionalized based on draft of the section.

Non-dimensional pressure, $C_{P}=\frac{p-p_{a}}{\frac{1}{2} \rho V^{2}(t)}$

where, $p_{a}=$ atmospheric pressure

$\rho=$ density of water

$V(t)=$ instantaneous entry velocity

Non-dimensional depth, $\zeta=\frac{z-z_{k}}{D}$

Where,

$z=$ vertical co-ordinate on the body surface

$z_{k}=$ vertical co-ordinate of the keel

$D=$ local vertical co-ordinate/ draft of the section

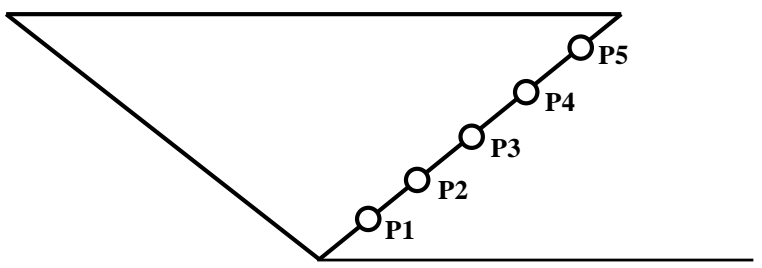

Fig. 7: Location of pressure evaluation points along the wedge section during experiment (Zhao et al., 1996).

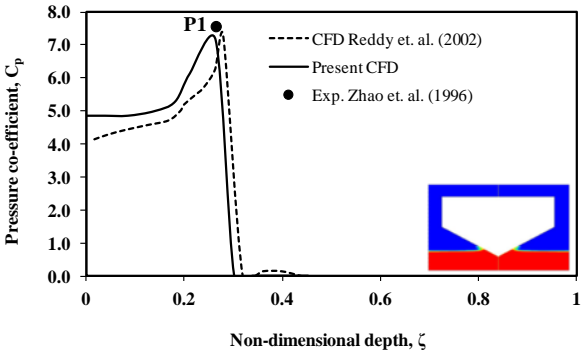

Fig. 8: Comparison of pressure distribution during water entry of wedge section at instance $0.00435 \mathrm{sec}$

\section{1 Local pressure predictions}

Fig. 7 shows the location of pressure evaluation points on the wedge section in the reference experiment. Local pressures along the sectional surface are evaluated at three time instances both for wedge and ship section. Figs. 8, 9 and 10 show the comparison of pressure distribution along the $30 \mathrm{deg}$. wedge section at time instances 
$0.00435 \mathrm{sec} .0 .0158 \mathrm{sec}$. and $0.0202 \mathrm{sec}$. respectively. Pressure distributions along the ship section at instances $0.06 \mathrm{sec} ., 0.07 \mathrm{sec}$. and $0.08 \mathrm{sec}$. are shown in Figs. 11, 12 and 13 respectively. The time instances for both of the sections are counted after initially touching the free surface. A non-dimensional depth of $\zeta=0$ corresponds to keel of the sections. It is seen from Fig. 8 that both computational results show similar trends i.e. pressure raises relatively slow near the wedge top and rapidly reaches to $\mathrm{P} 1$, and suddenly drops to zero in the vicinity of free surface. The present results indicate leftward shift with nearly equal value of peak denoted as P1.

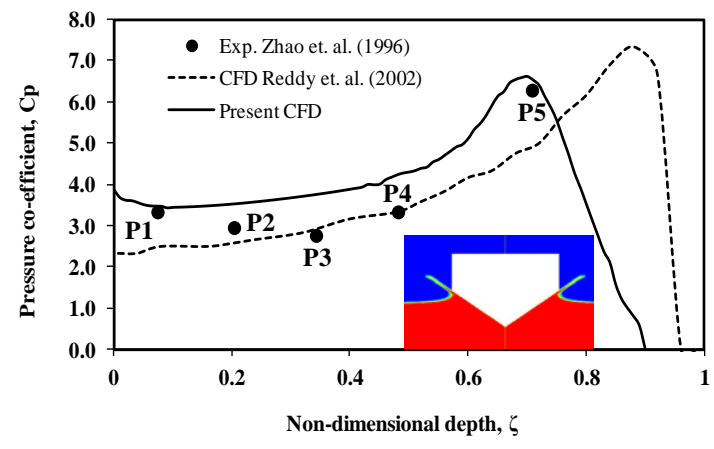

Fig. 9: Comparison of pressure distribution during water entry of wedge section at instance $0.0158 \mathrm{~s}$

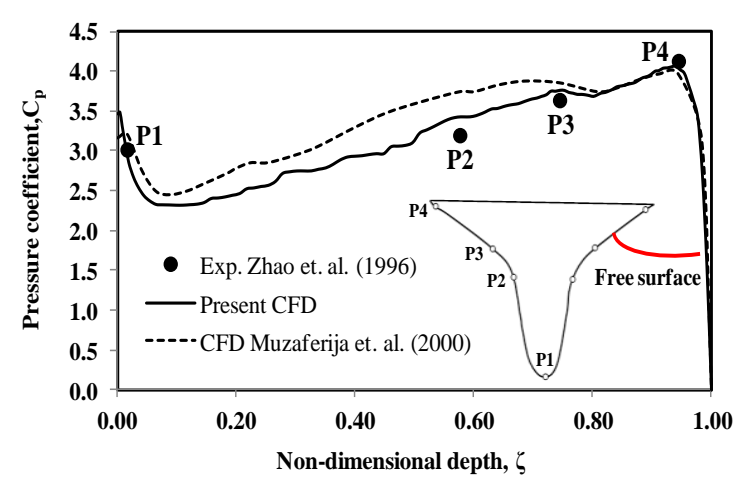

Fig. 11: Comparison of pressure distribution during water entry of flared ship section at instance $0.06 \mathrm{~s}$

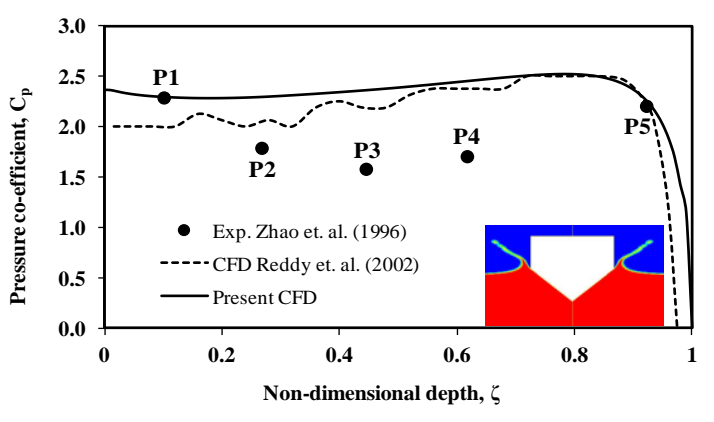

Fig. 10: Comparison of pressure distribution during water entry of wedge section at instance $0.0202 \mathrm{sec}$.

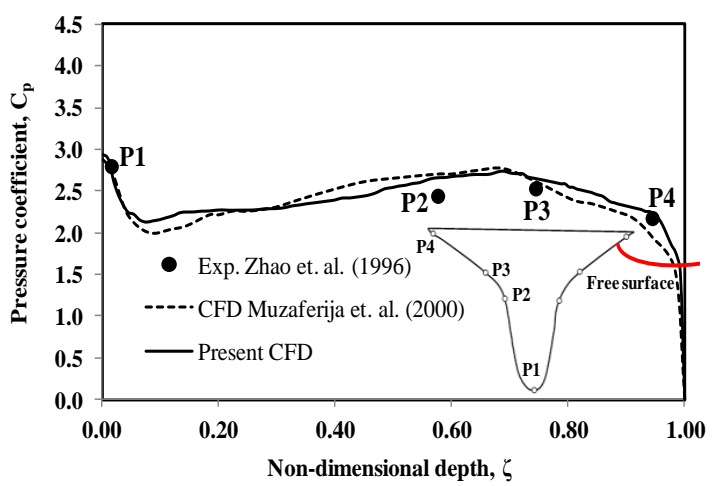

Fig. 12: Comparison of pressure distribution during water entry of flared ship section at instance $0.07 \mathrm{~s}$

In Fig. 9, it is clear that all measurement points, i.e., P1 through P5 are located under the free surface. Both results show similar trends but with more significant leftward shift is seen in the present results with better agreements of P1 and P5. The leftward shift is apparent due to influence of free surface. In Fig. 10, distribution of pressure is relatively flat, which is due to a fact that all points are below static free surface level, and the splash of the free surface is detached from the edge as shown in the figure. Consequently, the above mentioned leftward shift of the present results is not significant as others but agreement of P1 value is clearly improved. The improvement of P1 value, which is general trend shown in Figs. 8, 9 and 10 is likely due to advantage of the present scheme, which is the inclusion of velocity variation. In Figs. 11, 12 and 13, general trends of pressure are similar to those for wedge cases, but with clear differences near P1, which is apparent due to a fact that this time P1 is located bottom of the section, i.e., stagnation point, unlike the case for the wedge. Differences between two computational results are not as significant as the wedge cases, but the agreement with experimental data is clearly better for the present results. Zhao et al. (1996) has mentioned that the reason for variations in the middle stage of water entry comes from the three-dimensional effects in the experiment. Zhao et al. (1996) has also mentioned that there is some measurement error in the reference experiments.

\subsection{Time history of local pressure}

Figs.14, 15, 16, 17 and 18 show the comparison of time history of local pressure for the wedge sections at measurement points P1, P2, P3, P4 and P5 respectively. Both computational results predicted the similar trends 
of pressure time history at all measuring points but a better agreement of present numerical results is achieved. The possible reason is due to the exact treatment of impact velocity during water entry.

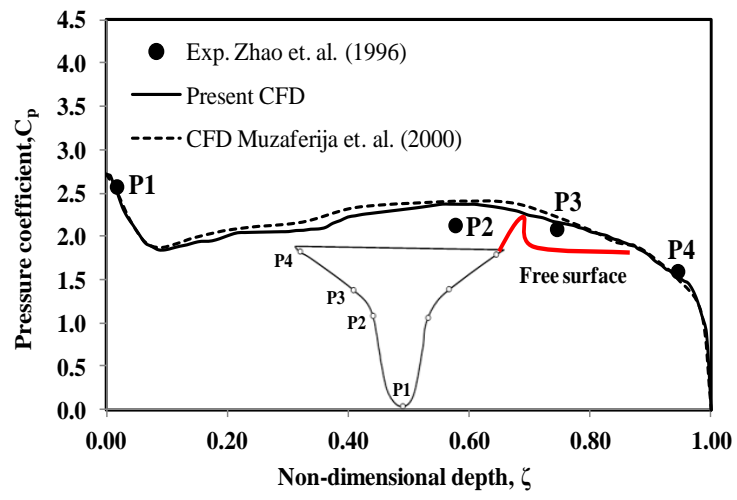

Fig. 13: Comparison of pressure distribution during water entry of flared ship section at instance 0.08 sec.

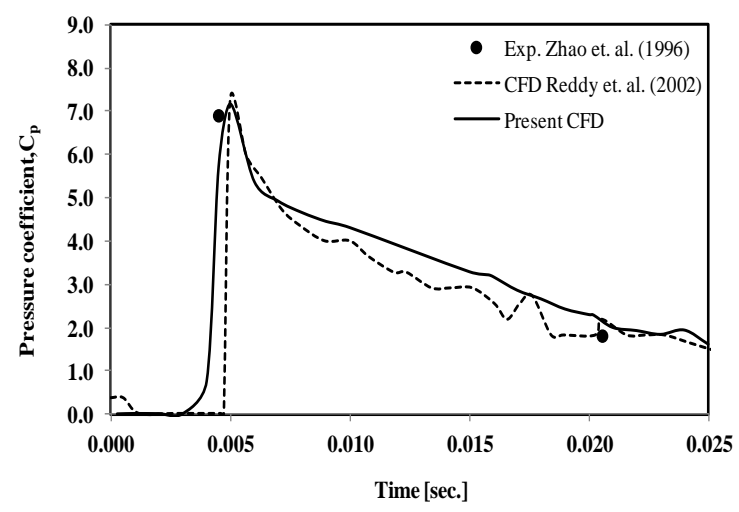

Fig. 15: Comparison of time history of pressure distribution at point P2 during water entry of wedge section

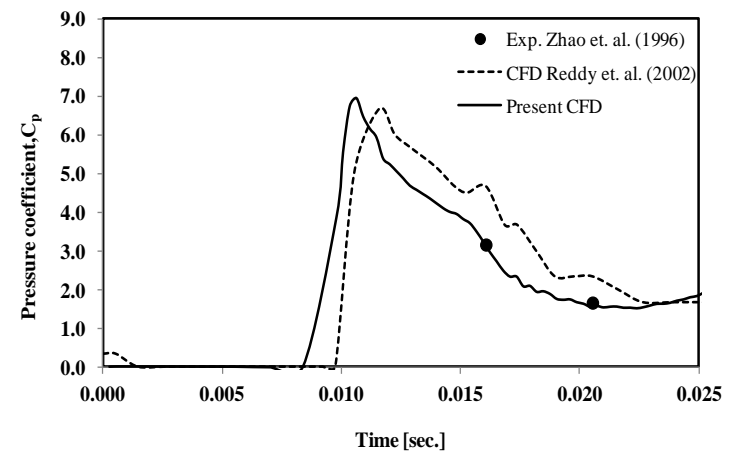

Fig. 17: Comparison of time history of pressure distribution at point P4 during water entry of wedge section

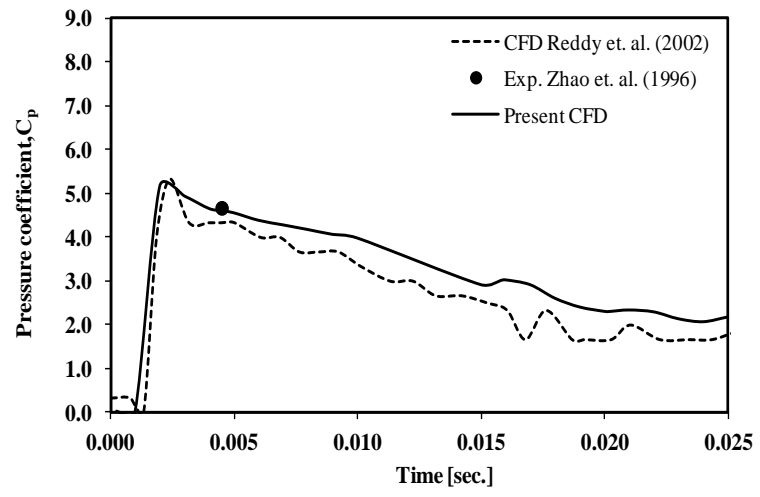

Fig. 14: Comparison of time history of pressure distribution at point P1 during water entry of wedge section

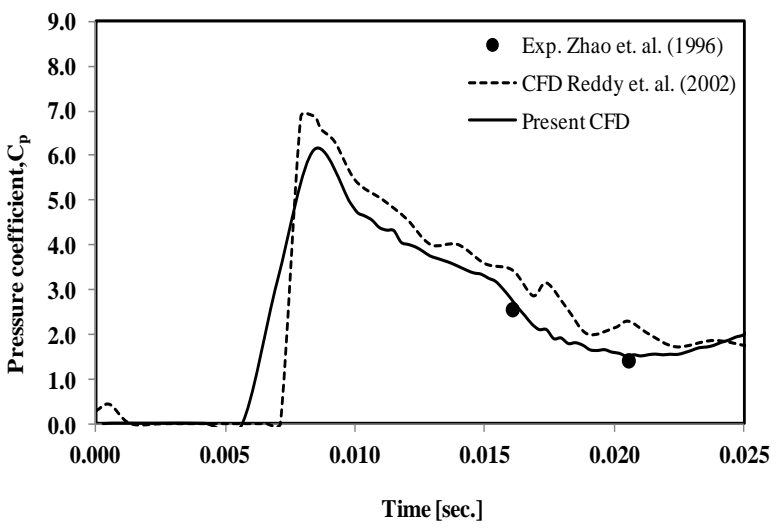

Fig. 16: Comparison of time history of pressure distribution at point P3 during water entry of wedge section

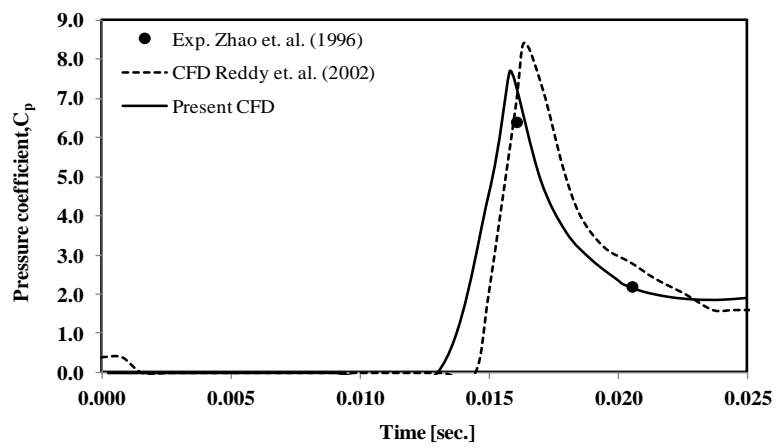

Fig. 18: Comparison of time history of pressure distribution at point P5 during water entry of wedge section

Figs. 19 and 20 show the time history of local pressure for ship section at non-dimensional depth, $\zeta=0.58$ and $\zeta=0.74$ respectively. In Figs. 19 and 20 , for $\mathrm{t}=0.06, \mathrm{C}_{\mathrm{p}}$ is larger at $\zeta=0.74$ than at $\zeta=0.58$, whereas at $\mathrm{t}=0.08, \mathrm{C}_{\mathrm{p}}$ is larger at $\zeta=0.58$ than at $\zeta=0.74$. Both numerical methods computed this trend with well agreement for present numerical method. 


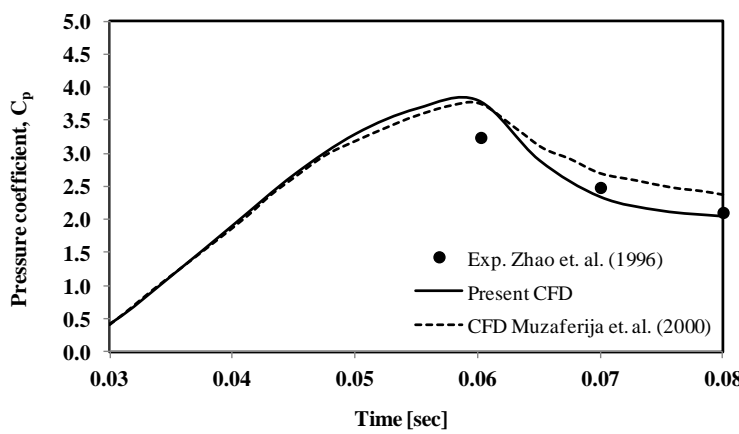

Fig. 19: Comparison of time history of pressure distribution at non-dimensional depth, $\zeta=0.58$ during water entry of flared ship section

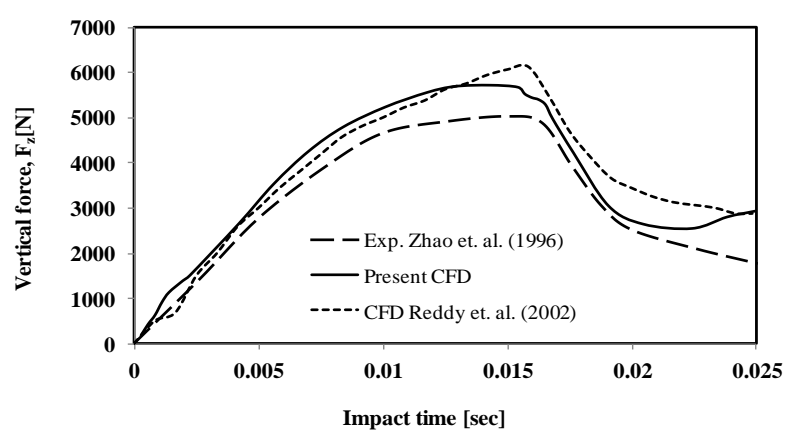

Fig. 21: Time history of vertical force on wedge section

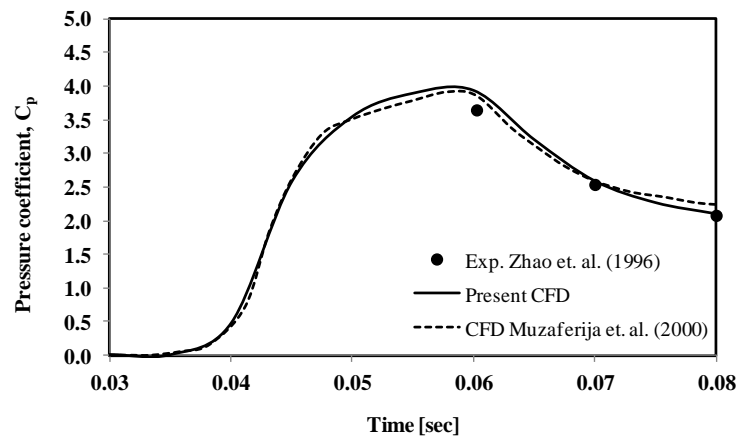

Fig. 20: Comparison of time history of pressure distribution at non-dimensional depth, $\zeta=0.74$ during water entry of flared ship section

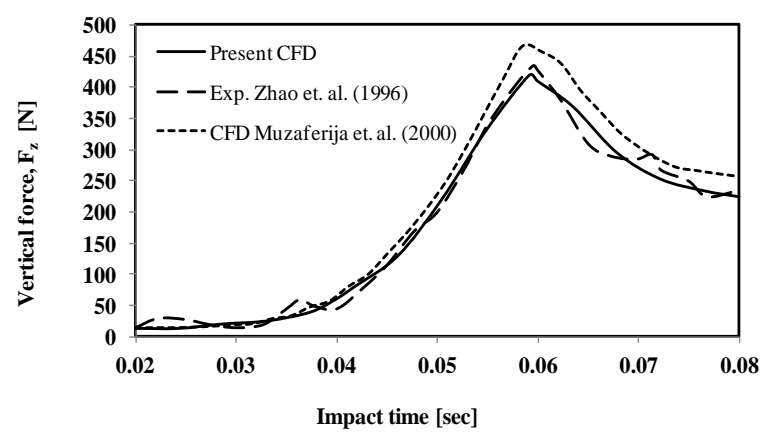

Fig. 22: Time history of vertical force on ship section

\subsection{Vertical force}

Vertical force is obtained by integrating the measured pressure along the surface. Figs. 21 and 22 show the comparison of vertical forces with experiment for wedge and ship section respectively. Present numerical method over-predicts the peak of vertical force for wedge section but for ship section it is in good agreement. Ship section in present 2D simulation is curved in nature. Therefore, the separation of flow, which leads to formation of jet during water entry for wedge and ship section, is different. In practical, the sectional geometry for experiments is three-dimensional and flow quantities are evaluated in two dimensional manner. So, the sectional shape has an effect on the evaluated quantities. To capture the three dimensional effects of shape on numerical results, usually, grids are extended in the longitudinal direction. Zhao et al. (1996) verified the threedimensional shape effects for bow flare section and concluded that three-dimensional effects causes $8 \%$ reduction of the force relative to two-dimensional force when the jets reached the knuckles.

\section{Conclusions}

A commercial Reynolds averaged Navier-Stokes based solver FLUENT ${ }^{\circledR}$ is used to verify the effects of velocity variation during water entry of $30 \mathrm{deg}$. wedge and ship section. Numerical results are compared with experimental results of Zhao et al. (1996) and numerical methods of Muzaferija et al. (2000) and Reddy et al. (2002). Local pressure and its time history are evaluated at the measuring points of experiments for wedge and ship section. Present numerical method predicted local pressure on the sectional surface accurately with experiments compared to numerical method for constant velocity water entry especially during initial and final stage of entry. Here, initial stage means after short time instance when keel of the sections touch the free surface and final stage is when the flow separates from the knuckle of the sections. Present numerical method also is in good agreement with experimental results for vertical forces in both wedge and ship section. Discrepancies in present numerical method with experiments can be further minimized by considering 3D shape effects. Since present research aims at studying 3D ship models, numerical simulations of three-dimensional water entry for wedge and ship sections are excluded. 


\section{Acknowledgement}

This research was supported by WCU (World Class University) program through the National Research Foundation of Korea funded by the Ministry of Education, Science and Technology (R31-2008-000-10045-0).

\section{References}

Arai, M. and Matsunaga, K. (1989): A numerical and experimental study of bow flare slamming, Journal of Society of Naval Architects, Japan, 166. http://dx.doi.org/10.2534/jjasnaoe1968.1989.166 343

Arai, M., Cheng, L.Y., Inoue, Y., Miyauchi, T. and Ishikawa, M. (1995): A study on slamming characteristics and optimization of bow forms of ships, Proceedings of 3rd International Symposium on Practical Design of Ships and Mobile Units, Seoul, Korea, September 17- 22.

Arai, M., Tasaki, R. (1987): A numerical study of water entrance of two-dimensional wedges effects of gravity, spray generation and vertical load, Proceedings of 3rd International Symposium on Practical Design of Ships and Mobile Units, Trondheim, Norway, June.

Cointe, R. and Armand, J.L. (1987): Hydrodynamic impact analysis of a cylinder, Journal of offshore Mechanics and Arctic Engineering, American Society of Mechanical Engineers (ASME), vol. 109, pp. $237-243$. http://dx.doi.org/10.1115/1.3257015

Faltinsen, O.M. (2000): Hydroelastic Slamming, Journal of Marine Science and Technology (JMST), vol.5, pp. 49-65. http://dx.doi.org/10.1007/s007730070011

Faltinsen, O.M., Landrini, M. and Greco, M. (2004): Slamming in marine applications, Journal of Engineering Mathematics 48, pp. 187-217. http://dx.doi.org/10.1023/B:engi.0000018188.68304.ae

Kapsenberg, G.K. (2011): Slamming of ships: where are we now? Philosophical Transactions of the Royal Society A 369, pp.2892-2919. http://dx.doi.org/10.1098/rsta.2011.0118

Howison, S.D., Ockendon, J.R. and Wilson, S.K. (1991): Incompressible water entry problems at small deadrise angles, Journal of Fluid Mechanics, vol. 222, pp.215-230. http://dx.doi.org/10.1017/S0022112091001076

Muzaferija, S., Peric, M., Sames, P.C. and Schellin, T.E. (2000): A two-fluid Navier-Stokes solver to simulate water entry, Proceedings of 22nd Symposium on Naval Hydrodynamics, pp. 638-651.

Reddy, D.N., Scanlon, T., Chengi, K. (2002): Prediction of slam loads on wedge section using computational fluid dynamics technique, Proceedings of 24th Symposium on Naval Hydrodynamics, pp. 37-49.

SNAME (1993): Notes on ship slamming, Society of Naval Architects and Marine Engineers (SNAME), Technical and Research Bulletin, pp. 2-30.

Tao, Z. and Incecik, A. (1996): Large amplitude ship motions and bow flare slamming pressures, Proceedings of the 15th International Conference on Offshore Mechanics and Arctic Engineering, OMAE, Florence, Italy.

Von Karman, T. (1929): The impact on sea plane floats during landing, Technical Report, NACA TN 321.

Wagner, H. (1932): Uber Stoss-und Gleitvorgange and der Oberflache von Flussigkeiten, Zeitschr. f. Angewandte Mathematik und Mechanik(ZAMM) vol. 12, no. 4, pp. 192-235. http://dx.doi.org/10.1002/zamm.19320120402

Zhao, R., Faltinsen O.M. and Aarnes, J. (1996): Water entry of arbitrary two-dimensional sections with and without flow separation, Proceedings of 21st Symposium on Naval Hydrodynamics, pp. 408-423, Trondheim, Norway. 